\title{
Reflexiones sobre la educación universitaria en pandemia. Experiencia en odontología
}

\section{Reflections on university education in a pandemic. Experience in dentistry}

\author{
María Belén Fernández \\ Licenciada en Ciencias de la Educación, Universidad de Buenos Aires, Argentina \\ Asesora pedagógica, Escuela de Odontología, Asociación Odontológica Argentina, Buenos Aires, Argentina
}

\begin{abstract}
Resumen
¿Cuándo fue que nos despertamos y nos dimos cuenta de que estábamos en una escena de película? Algo impensado para nosotros, un aislamiento, nos hizo sentir más que nunca que somos seres sociales. ¿Y qué ocurrió con la educación en este contexto?
\end{abstract}

El modo en que el ámbito universitario atravesó la pande- mia y la inclusión de la tecnología en la enseñanza odontológica invitan a reflexionar sobre los cambios que tuvieron lugar y que llegaron para quedarse.

Palabras clave: Educación odontológica, enseñanza en pandemia, tecnología educativa.

\begin{abstract}
That moment when we found ourselves in the middle of a movie scene.

Something unexpected for us, the isolation showed us the importance for human beings to socialise. The changes experienced in education during the lockdown in 2020 with
\end{abstract}

the inclusion of technology like internet in dental education, invites us to reflect about those changes and how they will affect dental education in the future.

Key words: Dental education, educative technology, teaching during the pandemic.
Nos encontramos frente a un nuevo panorama educativo; podríamos hablar de un nuevo paradigma, quizás. La universidad se reinventó para seguir adelante, y en poco tiempo se realizó un trabajo monumental: la virtualización de la educación universitaria. Docentes y estudiantes, reunidos a través de internet, lograron generar un vínculo diferente, una comunicación distinta. La transformación implicó esfuerzo y fue progresiva, "haciendo camino al andar".

Inicialmente, se vislumbró la necesidad de capacitación docente - en parte, para hacer factible la virtualidad-, y esta ayudó a potenciar la importancia de las estrategias de enseñanza. Anijovich y Mora $^{1}$ definen las estrategias de enseñanza como las decisiones que toma el docente para promover el aprendizaje de sus alumnos y que implican cómo enseñar un contenido. Estas estrategias dependen, por supuesto, de nuestra concepción acerca de la enseñanza.

Este contexto, en el que debimos diseñar nuevos materiales de estudio y pensar propuestas alternativas para un aula tan diferente a la de hace apenas un año, se presentó como un desafío para que exploráramos diversas posibilidades de involucrarnos en la enseñanza. Debimos aprender a ser flexibles para resolver cuestiones que van más allá de la relación docente-alumno, a tomar decisiones bajo nuevos criterios. El celular, el chat y la conectividad, todo eso que no utilizábamos en el aula — salvo de manera ocasional — se volvió moneda corriente. Aprendimos a re-relacionarnos, tejimos redes que construyeron puentes en la enseñanza, abrimos el diálogo. La curación de contenidos debió echar mano de la búsqueda de saberes confiables en internet. Nos abastecimos de conocimiento. 
Todo lo anterior nos permitió atravesar esta nueva etapa en la historia de la humanidad, y de la educación en particular, y adaptarnos a este complejo escenario para así sobrevivir al mejor estilo darwiniano.

El aislamiento borroneó de algún modo los límites entre lo público y lo privado. Nuestro espacio más íntimo, nuestro hogar, pasó a ser aula. La pandemia puso a los docentes en la pantalla: docentes "youtubers", creadores de podcasts y anfitriones de encuentros virtuales en vivo. Estas prácticas dieron lugar a gran cantidad de contenidos y les permitió a los estudiantes tener acceso a ellos, volver a ver los materiales para entender y estudiar con mayor profundidad.

La enseñanza virtual es una tarea compleja. En el caso particular de la odontología, podemos afirmar que sería insostenible en el largo plazo, ya que hay aprendizajes que necesariamente requieren de la enseñanza presencial. La odontología clínica es inconcebible sin la práctica en primera persona por parte de los estudiantes, bajo la tutela del docente. Sin embargo, tejer puentes tiene que ver también con enriquecer la formación con fundamentos teóricos más firmes para la práctica futura.

\section{¿Universidad y tecnología o tecnología para la universidad?}

Ahora bien, si reflexionamos sobre el rol de la tecnología en la educación y la manera en que esta influyó durante el aislamiento, confirmamos que la tecnología atraviesa nuestra vida desde hace rato. En algunos casos, se encuentra tan naturalizada que no lo advertimos. Pero la relación entre sociedad y tecnología no existe de forma aislada, y esto quedó demostrado por la adaptación que la educación universitaria debió realizar para poder continuar funcionando durante la pandemia de $2020{ }^{2}$

Asimismo, advertimos que la inclusión de la tecnología echó las bases de una nueva modalidad. En este tiempo escuchamos frases como "esto llegó para quedarse", "se vienen cambios a partir de esta nueva normalidad”, "ya nada volverá a ser lo mismo”. Estos dichos hablan de transformaciones relativas no solo a la tecnología, sino también a las estrategias educativas del docente. El quid de la cuestión tiene que ver con el modo en que incluimos a la tecnología, y la respuesta es que esta inclusión debe ser genuina. ${ }^{3}$ Esto quiere decir que no debería decidirse en función de la tecnología, sino comprendiendo qué buscamos enseñar, cómo se construye el conocimiento y qué esperamos de nuestros alumnos. Se trata de que la tecnología sea siempre un medio, nunca el fin.

La experiencia del aislamiento nos hizo reflexionar también sobre el sentido de la comunidad educativa, conformada por directivos, docentes, alumnos, administrativos. Lejos de mantenernos alejados, la tecnología aportó los medios para que la comunicación fuera efectiva. En relación con la idea de cooperación y responsabilidad compartida de la que hablan Burbules y Callister, ${ }^{4}$ se fueron formando nodos de trabajo en las distintas áreas a partir de la ubicuidad que caracteriza a la conectividad. La unión de los nodos evitó que nos perdiéramos en medio del aislamiento.

\section{¿Qué nos deja esta pandemia?}

Nuevos vínculos llegaron para quedarse de manera definitiva. Vínculos no sólo con la tecnología, sino con la enseñanza y los modos de pensarla.

Dado que la virtualidad no puede replicar la presencialidad (se trata de dos escenarios diversos, con complejidades diferentes), debimos reflexionar sobre la enseñanza, nos vimos obligados a repensarla.

La pandemia nos hizo revalorizar los encuentros presenciales, que nos brindan la posibilidad de intercambiar con nuestros alumnos.

El aislamiento dio lugar al surgimiento de nuevos escenarios para la enseñanza. Después de esta experiencia, la educación universitaria a partir de 2021 es diferente.

También quedó claro que es posible aprender durante toda la vida y en todos los ámbitos.

La cuestión de la evaluación del alumnado requiere un capítulo aparte. Queda como deuda la necesidad de idear propuestas que se corran de lo tradicional.

Nos espera un largo camino. La experiencia de 2020 ha sido apenas el inicio de una nueva mirada sobre la educación universitaria, en nuestro caso, en el ámbito odontológico.

\section{Referencias}

1. Anijovich R, Mora S. Estrategias de enseñanza: otra mirada al quehacer en el aula, $1^{\mathrm{a}}$ ed., Buenos Aires, Aique Grupo Editor, 2010.

2. Thomas H, Fressoli M, Lalouf A. "Introducción” en: Thomas H, Buch A. (coords.). Actos, actores y artefactos, $1^{\text {a }}$ ed., Bernal, Universidad Nacional de Quilmes, 2008, pp. 9-17.

3. Maggio M. Enriquecer la enseñanza, $1^{\text {a }}$ ed., Buenos Aires, Paidós, 2012.

4. Burbules N, Callister TA. Educación. Riesgos y promesas de las nuevas tecnologías de la información, $1^{\text {a }}$ ed., Buenos Aires, Granica, 2006.

Contacto:

MARía Belén Fernández belen.fernandez@aoa.edu.ar Junín 959, $4^{\circ}$ piso (C1113AAC) Ciudad Autónoma de Buenos Aires, Argentina 